\title{
FOREST SCHOOLS CURRICULA AND THE NEEDS OF OUR WOODS OPERATIONS
}

\author{
By W. A. Delahey \\ Canadian International Paper Co.
}

I

$\mathrm{N}$ this brief paper I am merely trying to bring out some points of interest which will lead to further discussion and perhaps result in sug. gestions which may be helpful to Deans of our Forest Schools in redrafting the courses of study followed at the different schools and bring these courses more in line with present day requirements.

This subject is not new and is not peculiar to any one school or any particular section of the country. It is one that has received a great deal of attention from University professors, Government Officials, Loggers, and Pulpwood Operators. Recent issues of the Journal of Forestry have contained much correspondence on this subject and a Committee of Amer. ican Foresters, under the Chairmanship of Col. Graves, with Professor Guise of Syracuse as Secretary, has been studying this subject for the past two years and there is no doubt the members will have collected some very valuable data and their report when submitted will be most useful. The prominence that is given to this subject confirms our views that there is need now for some drastic changes in the courses of study in the forestry faculties of our universities.

It is my thought that there is room in the courses for certain modifications and probably certain additional courses of studies. When we consider the success that many graduate foresters from our different forest schools have achieved, it is only natural that at least part of the credit for their successes should be given to the training they received during their courses of study. The directing heads of the Forest Services in the Provinces in the East and B.C. have all been trained in forestry at our universities. We all claim we have made great advances in forest fire prevention work and this largely through the research and organizing ability of men trained in forestry. During the past ten years many foresters have entered the employ of the Woodlands Departments of our pulp and paper companies and are meeting with very marked success in this field. Either these men have reached these positions through having been trained at our forest schools or in spite of it. My personal view is that their successes must largely be attributed to the training they received whilst studying forestry at college.

However changes seem to be the order of the day and certain changes may be made in our forestry courses to advantage. Oni looking back twenty-five or thirty years (some of us can remember a few years more 
than this), we find that our forest schools were organized in a day when forestry was practically an unknown subject, and foresters were still to be inflicted on the poor unsuspecting public. The men who drafted up the courses of studies had only the European courses as a background and the courses of study which they arranged were influenced py these. At that time the only openings for graduates in forestry were in the government service. Today, graduate foresters find their spheres of work in Government Research, Government Administration, Forest Fire Protection Work, Woodlands Operations, Pulp and Paper Companies and in General Business.

With these different lines of endeavor open and remembering the history of the organization of our schools, forestry courses must be modified if the students are to derive their full advantage. It is not to be expected that the training each man receives will fit him for every particular job without experience and it would also be unfair, I think, to ask a student to spend an additional two or three years in college to acquire knowledge that may not be of any great value to him. Therefore, it is in order to suggest that certain changes be made in the college course so that a student can have the advantage of training in the particular subjects that will be of the greatest value to him on graduation.

To get back more particularly to the subject under discussion, I will outline briefly my idea of the specialized knowledge that the paper companies' executives expect to find in foresters.

1. Training in the economic and industrial problems in forest ownership and utilization.

2. Training in technical forestry subjects.

3. Specialized training in practical logging engineering, certain basic silvicultural subjects, and civil and mechanical engineering.

The training of men to meet these requirements will require a very considerable change in the curricula of our different schools in which the courses are now particularly adapted to training men for the research field. My thought is that this can be arranged by giving students the privilege of choosing between courses of study designed to fit them for the research field or courses of study more adapted to meet industrial and Government administration requirements. One thing that we must not lose sight of is that no school can be expected to train men who on graduation will be the finished product.

This was very aptly brought home to me several years ago while listening to a lecture in my first year by the late Dean Galbraith of the Faculty of Applied Science, University of Toronto. He said the School of Science had never graduated an engineer, but that many graduates had developed into outstanding engineers. This same applies to our forest schools. We can only expect graduates from our schools to have basic 
training along lines that will fit them to enter minor positions in an operating department, and if they have received the proper training in college they will in a few years develop into very valuable men and be in a position to work out the solutions of many of our operating problems. We are naturally assuming that there is not much truth in the current stories regarding the standing of the pulp and paper industry and that the industry will continue to develop as it has done in the past.

If the question is asked: Is special training in forestry necessary to succeed in woodlands operations? My answer is "No" and "Yes." "No" because our woodlands have been operated successfully for many generations before our forest schools turned out graduates and today many of our most successful operations are being handled by men who have not been trained in a forest school, and "Yes" because special training in forestry and engineering is a decided advantage when we consider the problems that are facing us in organizing woods operations in such a large scale for long term schedules.

Should forest schools training be modified to meet woodlands operation requirements? My answer is a most emphatic "Yes." It is my thought that the course must be so designed that our students who plan to enter the field of woods operations will receive considerable practical engineering training in addition to their courses in silviculture, management, etc. I think that special attention must be given engineering courses such as Surveying, Strength of Materials, Internal Combustion Engines, Construction, etc. In addition to training on these engineering subjects, particular attention must be given during the course to cost accounting, more particularly training in estimating costs of different kinds of works and analy. sing operating costs.

I do not mean to name the particular courses now included in the curricula that should be dropped. I merely wish to point out that basic knowledge in certain engineering and accounting subjects will be of tremendous advantage to men graduating from our forest schools in the next few years and who are hoping to find employment in the woodlands de. partment of one of our paper companies.

\section{Land and Forest Surveying.}

Many will claim that good courses in surveying are given in all forest schools, but I am of the opinion that even more attention should be paid to this subject. We are encountering problems in forest survey work every day in the woods and it is most important that graduates entering woodlands work be fully equipped to handle any surveying problem that may be required in connection with the operation. 


\section{Mathematics.}

Additional training in mathematics will be required as a basis for the engineering subjects that I am suggesting and which I think should be included in a revised curriculum.

\section{Strength of Materials.}

I am not fully conversant with present day engineering courses, but we received a very useful course in this in the School of Science at Toronto about twenty years ago. I realize that in most of our construction jobs in the woods we do not bring into play any mathematical formulae to decide the size or kinds of timber, etc., that we should use. However, we all meet problems very often, where a knowledge of this sub. ject would be very useful. For example, - the size, kinds of cables and chains that should be used for holding booms, etc. I think an operator should be in a position to know just what cable or chain he should use for each given problem.

\section{Hydraulics.}

Certainly forestry students should have a course that will give them a working knowledge of hydraulics. From the first day we start in to cut logs in the woods we are interested in stream, flow and its control. In many of the areas in which we are working there are power developments and we are running up against the engineers of these companies and they continually refer to stream flow in cubic feet per second, etc. The men who have not had training in the subject such calculations are unintelligible.

\section{Construction.}

A forestry graduate should be equipped with some practical knowledge on construction, particularly buildings, bridges, flumes, dams, etc. No doubt a short course of study could be drawn up that would give a student at least some working knowledge of this particular subject. I realize that to give any scope to studies of the different problems to be dealt with under this subject would take many hours of lectures. But in spite of that, I do think a course of study, no matter how brief, would fit a grad. uate to meet some of the problems that will face him when he starts operating.

\section{Road Building.}

A course on road building will be useful to every forestry graduate. Here again it may be only an introductory course but it would at least form a basis for further studies after graduation.

\section{Mechanical Engineering.}

This is another subject that should receive considerable attention. More 
and more we are using mechanical devices on our woodlands operations. A forest graduate should have some working knowledge of internal combustion engines, particularly as to how they function. Most of us can step in a motor car, turn the key in the ignition, press the starter and the engine runs, but very few of us have more than a sketchy idea as to just what is happening under the hood.

We are continually faced with the problem of mechanical equipment and have to decide as to just what type of equipment is the best and whether on towing work we should use steam, gasoline or Diesel engines.

\section{Accounting Methods.}

I do not think any forestry graduate should go into operations without at least having had some training in accountancy, or plain book-keeping. Every day it is necessary for us to watch costs and to know how to study cost statements as worked out by our accountants. A brief course of study on this subject will be of great value to every graduate entering operations.

9. French.

Foresters who are employed in Eastern Canada particularly, will not minimize the value of a working knowledge in French. Surely with the courses in French that are given today at our English speaking universities, arrangements can be made to give a course in conversational French that will be of value to all graduates.

Another very vital problem for those in charge of our forest schools is that of selecting students to enter the study of forestry with a view to finding employment in woodlands operations.

It has been suggested that some schools situated in urban centres at. tract too many city trained boys. This may or may not be true. Others have suggested that a candidate for admission to study in a forest school should be required to produce a certificate showing that he has had at least one year's experience in woodlands operations in some capacity. This should tend to prevent disillusionment and will probably also discourage many boys who are not adapted to woods work and perhaps help to place them in some other special line of training for which they are better suited.

In a letter I received from A. W. Bentley, of the Newfoundland Power and Paper Utilities Corporation, he has brought out some valuable suggestions in connection with courses of logging and utilization as taught in the East today, and suggests as follows:

"That in the teaching in the East, the accent should not be placed on what is actually happening today, so much as the painstaking gather. ing of the fundamental basic facts of the amount of labor and material which enters into each step of the operation, and methods of analyzing this information intelligently, and the results of applying the findings 
to present practice. The keeping of systematic records and facts to guide and control an operation cannot be stressed too strongly, and the results which can be obtained from this information will depend on the ability of the man to interpret and use them."

"Members of various forestry faculties should spend a few months each summer on the operations in various sections of the country in order to see what is required from the graduates in the industries, so that they would be in a much better position to appreciate the problems which face present day graduates."

In closing I have a suggestion to make: It would be an advantage to each forest school to organize a small committee of its graduates to work with the faculty in a consulting capacity in drafting up courses of study. for the future.

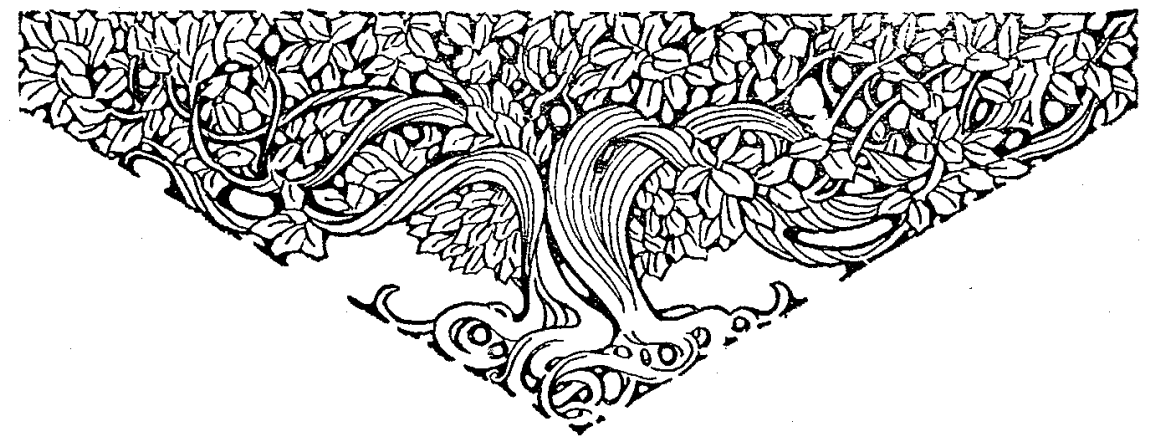

